UDC 343.148.4(470+571)

LBC 67.536(2Poc)

\title{
FORENSIC HANDWRITING EXAMINATION \\ IN THE LAW ENFORCEMENT ACTIVITIES OF THE RUSSIAN FEDERATION
}

\author{
Mikhail V. Bobovkin \\ Moscow University of the Ministry of Interior of Russia named after V.Ya. Kikot, Moscow, Russian Federation
}

\author{
Vitaliy A. Ruchkin \\ Volgograd State University, Volgograd, Russian Federation
}

Introduction: forensic handwriting examination is of great importance in law enforcement. The data from the official records of the forensic expert institutions of the Russian Federation indicate a tendency to increase in materials of forensic handwriting production, which is associated with the increase in the document flow in the country and a high level of its involvement in the criminal sphere of public life. In this regard, the authors set a goal to determine the current state and the direction of further development of the forensic handwriting examination in the Russian Federation. Methods: the methodological framework for the research are the methods of scientific cognition, among which the main are the methods of historicism, system, observation, comparison, analysis, synthesis, analogy, the study of expert practice, etc. Results: the author's standpoint is based on the opinion of the competent academic community, the data of sociological survey on the topical issues of the theory and methodology of forensic handwriting examination, the organization and tactics of the use of its results in law enforcement. Conclusions: the current state of forensic handwriting examination in the Russian Federation allows solving a wide range of identification and diagnostic problems. However, increasing the efficiency of its use requires further development in certain areas. Among them are theoretical, experimental, methodological, organizational and tactical, managerial, material and technical, international areas and others.

Key words: current state and use of results of forensic handwriting examination in law enforcement, identification and diagnostic tasks of forensic handwriting research, main directions of development of forensic handwriting in the Russian Federation.

УДК 343.148.4(470+571)

ББК $67.536(2 \mathrm{Poc})$

\section{СУДЕБНО-ПОЧЕРКОВЕДЧЕСКАЯ ЭКСПЕРТИЗА В ПРАВООХРАНИТЕЛЬНОЙ ДЕЯТЕЛЬНОСТИ РОССИЙСКОЙ ФЕДЕРАЦИИ}

\author{
Михаил Викторович Бобовкин
}

Московский университет МВД России им. В.Я. Кикотя, г. Москва, Российская Федерация

Виталий Анатольевич Ручкин

Волгоградский государственный университет, г. Волгоград, Российская Федерация

Введение: судебно-почерковедческая экспертиза имеет большое значение в правоохранительной дея-
тельности. Данные официальной отчетности судебно-экспертных учреждений Российской Федерации ука-
зывают на тенденцию к росту материалов судебно-почерковедческого производства, что связано с повыше-
нием документооборота в стране и высоким уровнем его вовлечения в криминальную сферу общественной
жизни. В этой связи авторы работы поставили цель определить современное состояние и направления даль-
нейшего развития судебно-почерковедческой экспертизы в Российской Федерации. Методы: методологи-
ческую основу исследования составляют методы научного познания, среди которых выделяются методы
историзма, системности, наблюдения, сравнения, анализа, синтеза, аналогии, изучения экспертной практики
и др. Результаты: изложенная в работе авторская позиция опирается на мнение компетентной научной 
среды, данные социологического опроса по актуальным вопросам теории и методики судебно-почерковедческой экспертизы, организации и тактики использования ее результатов в правоохранительной деятельности. Выводы: современное состояние судебно-почерковедческой экспертизы в Российской Федерации позволяет решать широкий круг идентификационных и диагностических задач. Однако повышение эффективности ее использования требует дальнейшего развития по отдельным направлениям. Среди них выделяются теоретическое, экспериментальное, методическое, организационно-тактическое, управленческое, материально-техническое, международное и др.

Ключевые слова: современное состояние и использование результатов судебно-почерковедческой экспертизы в правоохранительной деятельности, идентификационные и диагностические задачи криминалистического исследования почерка, основные направления развития судебного почерковедения в Российской Федерации.

\section{Введение}

Судебно-почерковедческая экспертиза имеет большое значение в правоохранительной деятельности. Данные официальной отчетности ЭКЦ МВД Российской Федерации и РФЦСЭ при Минюсте Российской Федерации указывают на сохранение с 1992 г. в постсоветской России тенденции к росту материалов судебно-почерковедческого производства, что связано с повышением документооборота в стране и высоким уровнем его вовлечения в криминальную сферу общественной жизни.

\section{Современное состояние} судебно-почерковедческой экспертизы

Современные достижения судебного почерковедения широко представлены в специальной литературе. Они формировались с периода греко-римской цивилизации и получили интенсивное развитие в середине 50 -х гг. $\mathrm{XX}$ века. Именно в это время получили научное обоснование категорические идентификационные выводы об исполнителе рукописи, что позволило более уверенно использовать эти суждения в экспертной практике.

Дальнейшие исследования способствовали преодолению сомнений в потенциале судебного почерковедения и росту его авторитета в России и за рубежом. При этом большое значение имеют труды В.Ф. Орловой, А.И. Винберга, С.И. Тихенко, Д.Д. Хмырова и других ученых.

В настоящее время судебное почерковедение представляет собой высокоразвитую область знаний, позволяющих решать широкий круг задач идентификационного и диагностического характера.
Идентификационные задачи связаны с установлением конкретного исполнителя рукописи либо факта выполнения множества рукописей (отдельных фрагментов) одним лицом или разными лицами [3].

В судебно-экспертной практике они являются преобладающими по отношению к иным задачам в общем массиве производства. При этом к числу наиболее распространенных объектов идентификационного исследования почерка относятся подписи $(65 \%)$ и краткие записи (30\%).

Диагностические задачи связаны с установлением личностных характеристик (качеств, свойств) исполнителя рукописи, внутренних или внешних условий ее выполнения. В настоящее время эти задачи делятся на следующие категории: общие, собственные, классификационные, ситуационные, временные [1].

\section{Использование}

\section{судебно-почерковедческой экспертизы}

\section{в правоохранительной деятельности}

Использование достижений судебного почерковедения распространяется на судопроизводство и иные сферы правоохранительной деятельности.

В уголовном судопроизводстве результаты судебно-почерковедческой экспертизы имеют доказательственное и ориентирующее значение. Они характеризуются объективными - строго научными показателями, не подверженными влиянию субъективных факторов. Это обеспечивает эффективное установление личности, свойств и состояний преступника, его соучастников, внешней обстановки письма, иных фактических обстоятельств, 
составляющих субъективную и объективную сторону по уголовному делу.

Данные социологических исследований показывают, что судебно-почерковедческая экспертиза в уголовном судопроизводстве является основной формой использования специальных знаний $(55,5 \%)$ по отношению к предварительным исследованиям почерка (15\%), несудебной (независимой, альтернативной) почерковедческой экспертизе (20 \%), материалам справочно-консультационной и профилактической деятельности (9,5 \%). С учетом ее процессуального статуса, она имеет высокий уровень доверия в оперативно-розыскной деятельности, предварительном следствии и судебном разбирательстве.

До возбуждения уголовного дела судебно-почерковедческая экспертиза используется весьма незначительно $(0,5 \%)$, так как во многом дублирует функции предварительного исследования. В ходе предварительного расследования осуществляется основная масса судебно-почерковедческих экспертиз (78 \%), из них дополнительных - $12 \%$ и повторных $-8 \%$. На судебном разбирательстве судебно-почерковедческая экспертиза используется менее активно $(21,5 \%)$, здесь преобладают повторные (12\%) и дополнительные исследования (6 \%).

По классу задач использование результатов судебно-почерковедческой экспертизы осуществляется следующим образом.

Производство идентификационных исследований почерка составляет 98,5 \%, диагностических $-1,5 \%$. Этот дисбаланс связан большей частью с непроцессуальной формой использования судебно-почерковедческой диагностики в ходе проведения оперативно-розыскных мероприятий и следственных действий «по горячим следам». Для его преодоления существенное значение имеет развитие современного потенциала судебно-почерковедческой диагностики и уровня осведомленности о нем лиц, обладающих правом назначения и использования результатов судебнопочерковедческой экспертизы. К сожалению, в настоящее время основные участники уголовного судопроизводства (судьи, следователи, дознаватели и др.) имеют низкий уровень знаний в этой области и чаще всего не видят разницы между достижениями судебно-почер- коведческой диагностики и псевдонаучного графологического учения.

Между тем использование судебно-почерковедческой диагностической экспертизы в уголовном судопроизводстве имеет большое значение. В частности, выводы эксперта о типологических свойствах, функциональном состоянии исполнителя рукописи, внешней обстановке письма способствуют установлению главных фигурантов преступления, разоблачению ложных показаний и алиби, инсценировки, фальсификации доказательств и т. д.

Напротив, весьма широкое использование судебно-почерковедческой диагностики наблюдается в гражданском судопроизводстве. Например, заключение эксперта о психопатологическом состоянии исполнителя рукописи является основанием для признания отдельных форм завещания, договоров займа, дарения ничтожной или оспоримой сделкой.

Использование результатов судебно-почерковедческой экспертизы на уровне вида ее задач связано с исследованием подписей $(65 \%)$, кратких записей $(30 \%)$ и текстов (5\%), что обусловлено характером современного документооборота.

Подпись является личным удостоверительным знаком конкретного лица и обязательным реквизитом документов, в том числе - с признаками интеллектуального и материального подлога. В настоящее время среди задач судебно-почерковедческого исследования подписного почерка наблюдается рост материалов в отношении подписей избирателей, собственников жилья (ТСЖ), вымышленных лиц, малоинформативных (банковских и др.) и современных подписей с использованием в транскрипции средств пиктографии, идеографии, необычного «двухэтажного» и «трехэтажного» строения.

В отношении кратких записей (до трех слов) чаще всего проводятся исследования рукописей удостоверительного (расшифровка ФИО) и административно-распорядительного («Разрешить», «Предоставить» и т. д.) характера. На современном этапе наблюдается рост исследования кратких записей в виде экстремистских лозунгов и призывов («Смерть русским» и др.) и актов вандализма - надписи и граффити на памятниках и мемориалах. 
Рукописные тексты в настоящее время незначительно представлены в судебно-экспертной практике. Как правило, этот вид почерковых объектов представляют рукописи малого и среднего объема (от 0,5 стандартного листа бумаги до 10 слов) в виде документов частного характера - писем, расписок, договоров займа, дарения, завещаний и т. д.

На уровне подвида задач судебно-почерковедческой экспертизы использование ее результатов связано с исследованием рукописей буквенного состава (75\%), смешанного буквенно-цифрового (10 \%) и буквенно-пиктографического, идеографического (2 \% от современных подписей и граффити), штрихового (13\% безбуквенных подписей).

Использование результатов судебно-почерковедческой экспертизы на уровне группы ее задач охватывает исследование рукописей, выполненных в обычных (65\%) и необычных (35 \%) условиях письма, связанных с влиянием естественных и искусственных сбивающих факторов.

В этой области наибольшую актуальность представляет решение задач, связанных с установлением необычного функционального состояния исполнителя рукописи (психопатология, наркотическое и алкогольное опьянение, аффект), намеренным (умышленным) изменением собственного почерка - автоподлог подписи, подражание буквам печатных шрифтов, скорописная маскировка, перемена привычной пишущей руки и др.

По сферам уголовного судопроизводства использование судебно-почерковедческой экспертизы распределяется следующим образом: при раскрытии и расследовании экономических преступлений - $35 \%$; против собственности - $40 \%$; государственной власти, интересов государственной службы и службы в органах местного самоуправления - $15 \%$; иные $-10 \%$.

В сфере экономических преступлений к использованию судебно-почерковедческой экспертизы чаще всего прибегают при раскрытии и расследовании легализации (отмывании) денежных средств или иного имущества, приобретенного в результате совершения преступления, регистрации незаконных сделок с недвижимым имуществом, незаконной банковской деятельности.
При этом основные экспертные задачи связаны, как правило, с исследованием множества почерковых объектов. Их решение требует больших затрат времени на систематизацию рукописей (иногда более 1000 экз.), широкомасштабный раздельный и сравнительный анализ, оценочную деятельность и выводы, оформление результатов экспертизы.

В сфере преступлений против собственности судебно-почерковедческая экспертиза используется для противодействия мошенничеству, причинению имущественного ущерба путем обмана или злоупотребления доверием. При этом объектами исследования чаще всего являются подписи и краткие записи. Большое значение имеет решение задач по идентификации исполнителей подписей от имени вымышленных лиц и подписей, выполненных с автоподлогом.

В сфере преступлений против государственной власти, интересов государственной службы и службы в органах местного самоуправления судебно-почерковедческая экспертиза используется главным образом в борьбе с нецелевым использованием бюджетных средств, взяточничеством, злоупотреблением должностными полномочиями и халатностью.

К иным сферам использования судебнопочерковедческой экспертизы относятся преступления, связанные с публичными призывами и содействием террористической деятельности, клеветой, незаконной выдачей или подделкой рецептов на получение наркотических средств или психотропных веществ, подделкой подписей избирателей и участников референдума, надругательством над местами захоронения умерших и др.

Результаты судебно-почерковедческой экспертизы широко используются и в розыске лиц - неустановленных преступников. В ходе этих мероприятий на основе комплексного решения диагностических и идентификационных задач составляется розыскная таблица, которая содержит данные о личности исполнителя рукописи (пол, возраст, профессия, образование и др.) и наиболее броские идентификационные признаки почерка. Основная цель ее использования - постепенное сужение круга подозреваемых и оперативное изъятие у них образцов почерка с целью последующего отождествления личности. 
Судебно-почерковедческая экспертиза используется также при ведении криминалистического учета поддельных медицинских рецептов на получение наркотических, психотропных и сильнодействующих лекарственных средств и образцов почерка лиц, их подделывающих. В настоящее время для противодействия мошенничеству, экономическим и иным преступлениям имеется потребность в формировании коллекций образцов почерка (подписей) лиц, замещающих отдельные должности государственной и муниципальной службы, политических деятелей, представителей культуры, искусства и др.

Кроме того, судебно-почерковедческая экспертиза имеет профилактическое значение. Ее результаты широко используются для предупреждения преступлений. В этой связи широко известны рекомендации экспертов-почерковедов относительно исследования оригинальных и электрографических изображений (копий) подписей, повышения информативности статутных подписей, разработки гибридных технологий и др.

\section{Основные направления развития}

\section{судебно-почерковедческой экспертизы в Российской Федерации}

Анализ научных источников, практики деятельности судебно-экспертных учреждений и уполномоченных органов в сфере назначения и использования результатов судебнопочерковедческой экспертизы позволяет установить следующие основные направления ее дальнейшего развития в Российской Федерации: теоретическое, экспериментальное, методическое и организационно-тактическое.

Кроме того, выделяются дополнительные (факультативные) направления. К ним относятся: правовое и материально-техническое обеспечение, организационно-управленческая деятельность, профессиональное обучение и повышение квалификации, международное сотрудничество.

Теоретическое развитие судебно-почерковедческой экспертизы имеет приоритетное - стратегическое значение. Это направление связано с повышением уровня судебного почерковедения, составляющего научную основу судебно-почерковедческой экспертизы и иных форм использования специальных почерковедческих знаний.

Инновационные разработки в области судебного почерковедения имеют широкомасштабный характер и охватывают частичное изменение структуры, содержания и в итоге названия данного раздела криминалистики и теории судебной экспертизы.

Известно, что термины «Судебное почерковедение» и «Судебно-почерковедческая экспертиза» сформировались в 70-80-х гг. прошлого века в системе Минюста России. Они четко указывают на процессуальный характер научной и практической деятельности в сфере судопроизводства. В то же время за ее пределами находятся непроцессуальные формы использования специальных почерковедческих знаний.

К ним относятся предварительные исследования почерка, независимая (альтернативная) экспертиза, несудебная справочноконсультационная и оперативно-розыскная деятельность специалиста-почерковеда, которые получили широкое распространение в правоохранительной деятельности.

Все они имеют правовую и иную специфику, требующую всестороннего научного изучения и регламентации в рамках более широкой области знаний. Представляется, что ее наиболее точным и приемлемым названием является «Криминалистическое почерковедение».

В целом дальнейшее развитие теории судебного или криминалистического почерковедения охватывает широкий круг научных исследований, связанных с определением:

- названия, предмета и системы дисциплины;

- понятия специальных почерковедческих знаний, отдельных форм и субъектов их использования в правоохранительной деятельности;

- методологии и фундаментальной базы;

- закономерностей формирования, функционирования, изменения письменного и письменно-двигательного навыка;

- основных криминалистических свойств письма и почерка.

Полагаем, что предмет криминалистического почерковедения составляют закономерности письма и почерка, процесса их ис- 
следования, разработка методов (методик) реализации отдельных форм использования специальных почерковедческих знаний в правоохранительной деятельности.

Следовательно, система этой дисциплины включает дополнительно к традиционным разделам методологию и организацию справочно-консультационной и розыскной деятельности специалиста-почерковеда.

На основе этой системы определяется понятие и круг специальных почерковедческих знаний, определяющих субъективную компетенцию эксперта и специалиста-почерковеда. В настоящее время к их определению нет единого межведомственного подхода (практического и образовательного), установленного федеральным стандартом.

Методологию и фундаментальную базу криминалистического почерковедения нужно дополнить за счет современных достижений в области физиологии движений и активности, психологии речевой деятельности, математики, информатики, кибернетики, права и других наук.

Большое значение имеет развитие знаний о механизме письма в условиях нормы и о влиянии отдельных сбивающих факторов. Здесь уместно вспомнить Е.Ф. Буринского автора термина «Судебное почерковедение», который еще в 1905 г. писал: «Задачи почерковедения вполне определены: найти законы зависимости между деятельностью органов, производящих письмо, и результатом этой деятельности - почерком» [2].

Эти знания выступают основой для изучения природы идентификационных и диагностических признаков и тесно связанных с ними криминалистических свойств письма и почерка - индивидуальности, динамической устойчивости, вариационности и разброса признаков, типологического своеобразия, избирательной и временной изменчивости.

Кроме того, теоретическое развитие судебного почерковедения требует определения:

1) общей системы идентификационных признаков письма (письменной речи и почерка) и частных систем признаков основных разновидностей почерка - буквенного, цифрового и подписного. Это актуально с учетом изменения современных норм прописи, тенденций по использованию в составе рукопи- сей пиктографических символов и идеографических знаков;

2) общей системы диагностических признаков письма, частных систем признаков, информативных с точки зрения решения отдельных задач диагностического исследования - общих, собственных, классификационных, ситуационных, временных;

3) единой стандартизированной терминологии судебного и криминалистического почерковедения.

Экспериментальное развитие судебно-почерковедческой экспертизы связано с дальнейшим совершенствованием знаний в области:

- частоты встречаемости и идентификационной значимости признаков почерка в условиях использования современных норм прописи. В итоге необходимо подготовить таблицы количественных данных и методические рекомендации по их использованию в решении задач, связанных с установлением исполнителя рукописи;

- корреляции типологии исполнителя, внутренних, внешних и временных условий выполнения рукописи с признаками письма. Эти данные составляют экспериментальную базу для развития методического потенциала криминалистической диагностики письма и почерка, а также разграничивают ее с псевдонаучными задачами графологии - криминологическими, политическими, религиозными и др.

Развитие методических основ судебнопочерковедческой экспертизы включает следующие задачи:

1) формирование общего учения о процессе криминалистического исследования письма и почерка;

2) совершенствование общей методики судебно-почерковедческой идентификации;

3) повышение эффективности ранее разработанных частных методик судебно-почерковедческой идентификации.

4) разработка частных методик решения идентификационных задач, связанных с исследованием иероглифических рукописей, подписей избирателей и подписей с современной транскрипцией, граффити и др.;

5) разработка методов определения и повышения априорной информативности почерковых объектов с использованием дости- 
жений математики, естествознания, нанотехнологии (гибридные подписи) и т. д.;

6) автоматизация детального (раздельного и сравнительного) исследования общих и частных признаков почерка, оценки их качественных и количественных показателей;

7) повышение эффективности полуавтоматических кибернетических методов идентификации и диагностики почерка, создание алгоритмов полной автоматизации решения экспертных задач по установлению исполнителя рукописи и условий ее выполнения;

8) совершенствование общей методики судебно-почерковедческой диагностики;

9) повышение эффективности ранее разработанных частных методик решения общих, собственных, классификационных, ситуационных задач судебно-почерковедческой диагностики с учетом изменения норм прописи;

10) разработка частных методов и методик судебно-почерковедческой классификации, связанных с исследованием рукописей, выполненных в необычных условиях письма;

11) создание частных методов и методик решения задач, связанных с установлением времени исполнения рукописей по признакам почерка;

12) совершенствование методики предварительного исследования почерковых объектов;

13) разработка средств научно-технического обеспечения рабочего места экспертапочерковеда;

14) сертификация и стандартизация методического обеспечения в сфере судебного почерковедения и др.

Организационно-тактическое развитие судебно-почерковедческой экспертизы связано с дальнейшим формированием знаний в cфepe:

1) тактики назначения и организации производства судебной и несудебной почерковедческой экспертизы, предварительного исследования почерка;

2) тактики назначения и организации производства справочно-консультационной, профилактической, оперативно-розыскной деятельности эксперта и специалиста-почерковеда;

3) взаимодействия между субъектами правоохранительной деятельности в сфере использования специальных почерковедческих знаний;

4) оценки и использования результатов судебно-почерковедческой экспертизы и иных форм использования специальных почерковедческих знаний в правоохранительной деятельности.

\section{Выводы}

Современное состояние судебно-почерковедческой экспертизы в Российской Федерации позволяет решать широкий круг идентификационных и диагностических задач. В целом они связаны с установлением данных, имеющих в правоохранительной деятельности доказательственное, ориентирующее и профилактическое значение. Повышение эффективности использования судебно-почерковедческой экспертизы требует ее дальнейшего развития по отдельным направлениям, которые осуществляются в русле общей тенденции развития криминалистики и судебной экспертизы. Полагаем, что этот подход в комплексе с иными научно-практическими действиями непосредственно влияет на уровень законности и правопорядка в стране.

\section{СПИСОК ЛИТЕРАТУРЫ}

1. Бобовкин, М. В. О систематизации диагностических задач судебно-почерковедческой экспертизы / М. В. Бобовкин, Н. А. Соловьева // Судебная экспертиза. - 2013. -№ 3 (35). - С. 26-31.

2. Буринский, Е. Ф. Судебная экспертиза документов, производство ее и пользование ею / Е. Ф. Буринский. - СПб. : Тип. СПб. товарищества печати и издат. дела «Труд», 1903. - 386 с.

3. Словарь основных терминов судебно-почерковедческой экспертизы / В. Ф. Орлова [и др.]. М. : РФЦСЭ, 2003. -84 c.

\section{REFERENCES}

1. Bobovkin M.V., Solovyeva N.A. O sistematizatsii diagnosticheskikh zadach sudebnopocherkovedcheskoy ekspertizy [On Systematizing Diagnostic Tasks of Forensic Handwriting Analysis]. Sudebnaya ekspertiza, 2013, no. 3 (35), pp. 26-31.

2. Burinskiy E.F. Sudebnaya ekspertiza dokumentov, proizvodstvo ee i polzovanie eyu [Forensic Analysis of Documents: Procedure and Use]. Saint Petersburg, Tip. SPb. tovarishchestva pechati i izdat. dela «Trud», 1903.386 p. 


\section{ГЛАВНАЯ ТЕМА НОМЕРА}

3. Orlova V.F., et al. Slovar osnovnykh terminov sudebno-pocherkovedcheskoy ekspertizy [The
Dictionary of Main Terms of Forensic Handwriting Analysis]. Moscow, RFTsSE Publ., 2003. 84 p.

\section{Information about the Authors}

Mikhail V. Bobovkin, Doctor of Sciences (Jurisprudence), Professor, Department of Researching Documents, Educational and Scientific Complex of Forensic Examination, Moscow University of the Ministry of Interior of Russia named after V.Ya. Kikot, Akademika Volgina St., 12, 117437 Moscow, Russian Federation, mbobovkin@yandex.ru, support@mosu-mvd.com.

Vitaliy A. Ruchkin, Honored Scientist of the Russian Federation, Doctor of Sciences (Jurisprudence), Professor, Head of Department of Physical Materials Science and Forensic Examination, Institute of Priority Technologies, Volgograd State University, Prosp. Universitetsky, 100, 400062 Volgograd, RussianFederation, v.ruchkin@yandex.ru, priori@volsu.ru.

\section{Информация об авторах}

Михаил Викторович Бобовкин, доктор юридических наук, профессор кафедры исследования документов учебно-научного комплекса судебной экспертизы, Московский университет МВД России им. В.Я. Кикотя, ул. Академика Волгина, 12, 117437 г. Москва, Российская Федерация, mbobovkin@yandex.ru, support@mosu-mvd.com.

Виталий Анатольевич Ручкин, заслуженный деятель науки Российской Федерации, доктор юридических наук, профессор, заведующий кафедрой физического материаловедения и судебной экспертизы института приоритетных технологий, Волгоградский государственный университет, просп. Университетский, 100, 400062 г. Волгоград, Российская Федерация, v.ruchkin@yandex.ru, priori@volsu.ru. 